\title{
Die ältesten Vyšehrader Urkunden und ihre Rolle in der Gedächtnisbildung des dortigen Stiftskapitels
}

\section{The oldest charters from Vyšehrad and their importance in the memory building of the Vyšehrad chapter}

Lukáš Reitinger / 64694@mail.muni.cz

Ústav pomocných věd historických a archivnictví FF MU

\begin{abstract}
Bohemian prince and first king Vratislav II († 1092) encouraged the building of an exemptchapter dome, dedicated to St. Peter and Paul opposite to Prague castle. It was situated near the second important dwelling of the dynasty, the Přemyslid castle of Vyšehrad on the left shore of Vltava river. In the first years of the chapter's existence, under the rule of Vratislav II and Soběslav I (1125-1140), there were four phases of associated privilege making. The study emphases on those charters that contain the chapter's justification and some references to alleged privileges of the founder Vratislav II and pope Alexander II. The same accounts for the charter's placement in the memoria of the chapter.
\end{abstract}

\section{Keywords}

charters; memory; damnatio memoriae; Vyšehrad chapter, duke and King Vratislav II of Bohemia; pope Alexander II; pope Gregor VII; antipope Clemens III; Bohemia 
Der böhmische Fürst und (seit 1086) erster König Vratislav II. (1061-1092) ließ in den 60. und 70. Jahren des 11. Jahrhunderts in der Nähe von Prager Burg auf dem gegenüberliegenden Ufer des Flusses Moldau auf der zweitbedeutendsten přemyslidischen Burg Vyšehrad (Wischehrad) ein exemtes Kollegiatstift der Heiligen Peter und Paul erbauen. ${ }^{1}$ In die Zeit der Entstehung und des Anfangs der Kirche unter die Regierung von Vratilav II. und seinen Sohn Soběslav I. (1125-1140) melden sich vier Privilegien, deren Wortlaut einander in gewissem Maße nahe steht. ${ }^{2}$ Die neueste Diskussion über diese Urkunden beeinflusst vor allem die neuerliche Schlussfolgerung, dass der erste Fortsetzer der Chronik von Cosmas, der sog. Kanoniker von Vyšehrad, schrieb nach Allem nicht auf Vyšehrad, sondern im Prager Domkapitel. ${ }^{3}$ Auch dieser Deutungswandel trug zu meinen früher publizierten Schlussfolgerungen bei, dass die zwei Urkunden von Soběslav I., welche in jüngeren Abschriften erhalten worden sind, sich als authentisch zeigen. ${ }^{4}$ Hier richte ich mein Augenmerk auf die Urkunden, die mit der Begründung des Siftskapitels und ferner mit den angeblichen Privilegien des Stifters Vratislav II. und des Papstes Alexander II. verbunden sind, insbesondere interessiert mich ihr Standort in der memoria dieses Chorrherrenstiftes.

Die angebliche Verfügung des Vyšehrader Stifters Vratislav ist in vier Fassungen (A, B1, B2, C) erhalten ${ }^{5}$ und wie ich darauf bereits hingewiesen hat, der Aufzeichnung von 1470 zufolge gab es ursprünglich fünf Exemplare der Urkunden von Vratislav. Eines davon ist somit verlorengegangen. ${ }^{6}$ Von den erhaltenen vier Fassungen ist die sog. Fassung A die älteste, welche von späteren Schreibern überarbeitet und ergänzt wurde. Die Hand des ersten Schreibers wurde paläographisch entweder in die erste oder zweite Hälfte des

1 Zur Bedeutung der Burg Vyšehrad unter Přemysliden Pleszczyński, Andrzej: Vyšehrad, rezidence českých panovniků. Studie o rezidenci panovnika raného středověku na př́kladu českého Vyšehradu. Praha 2002; Wihoda, Martin: Pruni česká království. Praha 2015, S. 156-166; Reitinger, Lukáš: Vratislav. Pruni král Čechů. Praha 2017, S. 154-249. Archeologische Erkentnisse versammelten Nechvátal, Bořivoj: Kapitulni chrám sv. Petra a Pavla na Vyšehradě. Archeologický výzkum. Praha 2004; Rotunda sv. Martina a bazilika sv. Vavřince na Vyšehradě. Hg. von Bořivoj Nechvátal u.a. Praha 2009; Mucha, Václav - Nechvátal, Bořivoj - Varadzin, Ladislav et al.: Vyšehrad. Knižecí a královská akropole. Svědectvi archeologie. Praha 2015.

2 Codex diplomaticus et epistolaris regni Bohemiae (= CDB) I. Ed. Gustav Friedrich. Pragae 1905-1912, S. 371-391, Nr. 387; S. 111-115, Nr. 111; S. 405-406, Nr. 393; S. 365-367, Nr. 384; bzw. Gründung der Kirche von Wischehrad. In: Cosmae Pragensis Chronica Boemorum, Monumenta Germaniae historica (= MGH), Scriptores rerum Germanicarum in usum scholarum separati editi (= SRG) Nova Series II. Hg. von Berthold Bretholz unter Mitarbeit von W. Weinberger. Berolini 1923, S. 252-254.

3 Reitinger, Lukáš: Psal tzv. Kanovnik vyšehradský opravdu na Vyšehradě? Prvni Kosmův pokračovatel v kontextu dějepisectvi přemyslovského věku. Český časopis historický (=С̌C̆H) 113, 2015, S. 635-668.

4 Ders.: Nejstarši vyšehradské listiny. In: Pomocné vědy historické v současné historiografii a archivnictví. Hg. von Marie Bláhová - Mlada Holá - Klára Woitschová. Praha 2017, S. 214-244, hier S. 215-227; aktueller ders.: Vratislav, S. 163-170.

5 Národní archiv (= NA) Praha, Archiv kolegiátní kapituly vyšehradské (= KVš), Urkunden Inv. Nr. 1, 2, 3, 4; CDB I, S. 371-391, Nr. 387.

6 NA Praha, KVš, Inv. Nr. 10, Buch Nr. 27, Fol. 45r: unam cistulam [...] cum pergamenis literris fundatorum felicissime memorie Wratislai ducis et primi regis Bohemie in et super donationem bonorum pro eadem ecclesia, que sunt numero quinque. Das fünfte heute verlorengegangene Exemplar der Urkunde wurde auch an der Rückseite des Exemplar C von einem Hand des 15. Jahrhunderts bemerkt. NA Praha, KVš, Urkunden Inv. Nr. 4; Wratislaus primus rex Bohemie fundator ecclesie Wissegradenisis quinqe littere sue verusque et eiusdem tenoris dat Wissegrad. Weiter vgl. Reitinger, L.: Vratislav, S. 176-178. 
12. Jahrhunderts datiert, zuletzt auch ins erste Drittel des 12. Jahrhunderts. ${ }^{7}$ Bei dieser relativ breitgefassten Datierung wurde aber die Beobachtung des Regionalhisotrikers Rudolf Schreibers von 1936 übersehen, welcher auf die mögliche viel präzisere Datierung aufmerksam machte. ${ }^{8}$ Denn der erste Schreiber des Privilegiums schrieb auch die Bestimmung, dass das Siftskapitel jedes „zehnte Pfund aus dem Tribut über ganz Böhmen, einschließlich Sedlec“ - „Decimam marcam de tributo per totam Boemiam etiam Sedlcih“ in Anspruch nehmen kann. ${ }^{9}$ Die Sedletzer Region stellte, bis auf einen kurzen Zeitabschnitt, über das ganze Frühmittelalter einen integralen Teil des Fürstentums Böhmen dar. Etwa in den Jahren 1181/1182-1193 hielt Sedlec als direkten Besitz der Kaiser Friedrich Barbarossa und es gehörte nicht zu Böhmen. ${ }^{10}$ Daher hatte nur in dieser kurzen Zeit oder kurz später die Hervorhebung der Sedletzer Region neben „ganz Böhmen“ ihren Sinn und somit ist es offenkundig, dass die Fassung der ältesten erhaltenen angeblichen Vratislavs Urkunde (Version A) eben in diesem Zeitabschnitt entstanden haben musste.

Die ältesten von den vier erhaltenen Urkundenfälschungen des Stifters (Fassung A) verfertigte zwar der unbekannte Fälscher erst nach 1182, es ergibt sich aber darüber hinaus die Frage, ob derselbe Fälscher als Urheber des ganzen Schriftstücks zu betrachten ist, oder lediglich eine älteres Vorbild zu diesen Zwecken redigiert wurde. Wenn das der Fall war, stehen wir vor dem Problem, welches Gepräge die erwähnte Vorlage hatte. Dürfen wir irgendeine authentische Urkunde von Vratislav II. voraussetzen, ${ }^{11}$ oder handelte es sich um eine Fälschung, ${ }^{12}$ die erst nach 1182 ganz niedergeschrieben wurde und anhand einer Traditionsaufzeichnung oder eines Vermögensverzeichnisses aus der zweiten Hälfte des 12. Jahrhunderts hergestellt worden ist. Zu dieser Meinung neigte vor allem Jiřina Psíková wie auch weitere und zwar mit dem Hinweis auf die vermutete Tatsache, dass die angebliche Urkunde alle Güter umfasst, welche das Vyšehrader Chorrherrenstift in der Zeit der Entstehung der Fälschung hielt. Die Fälschung selbst

7 Palacký, František: Dějiny národu českého v Čechách a v Moravě I-2. Praha 1854, S. 393; CDB I, S. 371-391, Nr. 387; Nový, Rostislav: Přemyslovský stát 11. a 12. století. Acta Universitatis Carolinae, Philosophica et Historica monographia 43. Praha 1972, S. 127; ders.: Diplomatické poznámky k donačním listinám českých klášterủ a kapitul do konce 12. století. Studia mediaevalia Pragensia 2, 1991, S. 125-146, hier S. 135; Jagošová, Anna: Zakladacia listina vyšehradskej kapituly CDB I, 387. In: Prameň - jeho funkcia, význam, interpretácia a limity v historickom výskume. Hg. von Alena Feriancová - Miroslav Glejtek. Nitra 2010, S. 41-51, hier S. 46.

8 Schreiber, Rudolf: Die Stellung des mittelalterlichen Elbogener Landes zu Böhmen. Mitteilungen des Vereins für die Geschichte der Deutschen in Böhmen 74, 1936, S. 1-28, 81-103, hier S. 4f.

9 CDB I, S. 386, Nr. 387.

10 Kejř, Jiří: Císař Friedrich Barbarossa jako pán západočeské provincie sedlecké (loketské). In: Pocta Václavu Vaněčkovi k 70. narozeninám. Praha 1975, S. 11-27.

11 So CDB I, S. 372, Nr. 387 (Komentar von G. Friedrich); Hrubý, Václav: Tři studie k české diplomatice. Hg. von Jindřich Šebánek. Brno 1936, S. 151-160; Novotný, Václav: České dějiny I-2. Od Břetislava I. do Přemysla. Praha 1913, S. 142-143, Anm. 1, S. 145, 282f; Jagošová, A.: Zakladacia listina, S. 47f.

12 In dieser Sinne Psíková Jiřina: Př́spěvky k diplomatice vyšehradských listin 12. století. Archivum Trebonense 2, 1973, S. 1-43, hier S. 28; Pražák Jiří: Rozšíreni aktů v přemyslovských Čechách. K počátkům české listiny. In: Pocta akademiku Václavu Vaněčkovi k 70. narozeninám. Praha 1975, S. 29-40, hier S. 34, 36; Bláhová, Marie: Die Herrscherurkunden in den böhmischen Ländern in der Zeit der premyslidischen Fürsten (bis zu Ende des 12. Jahrhunderts): Formular - Stilistik - Funktion. In: Urkunden und ihre Erforschung. Zum Gedenken an Henrich Appelt. Hg. von Werner Maleczek. Veröffentlichungen des Instituts für Österreichische Geschichtsforschung 62. Köln - Wien 2014, S. 207-225, hier S. 208. 
umfasst dieser Interpretation zufolge die Aufzeichnung der Donationen, welche die Kanoniker im 12. Jahrhundert erwarben, vor der Entstehung dieser Fälschung, also etwa vor dem Jahre 1182, ${ }^{13}$ sollte aber zudem an eine interessante und übersehene Tatsache erinnert werden. Bis auf zwei Ausnahmen, umfasst die Fälschung nicht die Güter und Abgaben, von denen wir aus einer Anzahl von anderen Quellen wissen, dass sie im Laufe des 12. Jahrhunderts das Stiftskapitel erlangte. Obwohl in der ältesten erhaltenen Gründungsfälschung in den Aufzeichnungen über die einzelnen Dörfer und Abgaben durchlaufend ihre Beschreibung präzisiert wurde, ferner die Liste der geschenkten Menschen, die mit der gegebenen Lokalität verbunden waren, aktualisiert und in den späteren Jahren weitere Schenkungen mit anderer Hand zugeschrieben, im Grunde begegnen wir in der ersten Schreiberschicht der angeblichen Urkunde von Vratislav II. nicht der Zusammenfassung anderer uns bekannten Gaben, die Chorrherren im Laufe des 12. Jahrhunderts erlangten. ${ }^{14}$ Solcher beinahe kritischer Ansatz eines etwaigen Fälschers ist aber als äußerst unwahrscheinlich zu betrachten, daher darf berechtigterweise vorausgesetzt werden, dass die erhaltene Fälschung von einem authentischen Schriftstück des 11. Jahrhunderts ausgeht.

Diese Unvollständigkeit und fehlende Aktualität im Bezug auf die Besitzungen des Stiftskapitels stellt aber nicht das einzige Indiz der Voraussetzung dar, dass den erhaltenen Fälschungen der Königsurkunde ein älteres Schriftstück vorkam, gegebenenfalls ein authentisches Dokument des Herrschers vom 11. Jahrhundert. Einerseits sind mit Vratislav II. die Anfänge des Urkundenwesens der böhmischen Herrscher verbunden, ${ }^{15}$ andererseits können interessante Zusammenhänge aufgedeckt werden, wenn wir die besprochene Fälschung in den Kontext der zeitgenössischen Produktion der Schreiberwerkstätte der Vyšehrader Kanoniker im 12. Jahrhundert setzen. In der erwähnten Schreiberwerkstätte sind im 12. Jahrhundert die Urkunden Soběslav I. entstanden, in denen daran erinnert wird, wie Vratislav die Kirche von Vyšehrad gegründet hat und mit wie vielen Präbenden er sie ausstattete. ${ }^{16}$ In ein weiteres auf Vyšehrad vollständig gefälschtes Privileg des Papstes Alexander II. mit dem Einführungskomentar haben die Kanoniker damals viele Detailinformationen über den Verlauf der Gründung der Kirche eingegliedert, einschließlich des

13 Hrubý, V.: Tři studie, S. 154ff; Nový, R.: Přemyslovský stát, S. 127; Psíková, J.: Př́spěvky k diplomatice, S. 19, 21; Hledíková, Zdeňka: Ke kulturním poměrưm vyšehradské kapituly počátkem 13. století. Folia historica Bohemica 2, 1980, S. 129-173, hier S. 133, 155, Anm. 18, S. 156, Anm. 21.

14 Ausführlicher Reitinger, L.: Vratislav, S. 172-174.

15 Hrubý, V.: Tři studie, besonders S. 9-12, 73-79, 81-83, 131-138, 151-159, 166; Šebánek, Jindřich - Dušková, Sáša: Česká listina v době přemyslovské (Nástin vývoje). Sborník prací filozofické fakulty brněnské univerzity (= SPFFBU) C 11, 1964, S. 51-72, hier S. 54-55; Bistřický, Jan: Übersicht über das Urkundenwesen der böhmischen Herrscher bis zum Jahre 1197. In: Typologie der Königsurkunden. Hg. von Jan Bistřrický. Olomouc 1998, S. 227-233; Dolista, Karel: Ještě k listinám hradištského kláštera z roku 1078. Československý časopis historický (= ČsČH) 19, 1971, S. 111-118; Zaoral, Prokop: K zakládací listině hradištského kláštera z roku 1078. ČsČH 16, 1968, S. 275-283 ; Bistřický, Jan: Zakládaci listiny kláštera Hradiska u Olomouce a počátky české panownické listiny. Vlastivědný věstník moravský 45, 1993, S. 131-136; Reitinger, L.: Vratislav, S. 136-138, $151-154$, S. $178-180$.

16 CDB I, S. 405, Nr. 393: ecclesie Wissegradensi, quam pro remedio anime sue pater meus construxit, rex Vratizlaus [...] canonici cum duodecim [...] a patre meo constitutis; CDB I, S. 111, Nr. 111: in secreto cordis mei deliberavi patris mei, regis videlicet Wratizlai, monasterium in Wisegrad civitate situm. 
rituellen Aktes, wo Vratislav persönlich in das Fundament 12 Körbe der Tonerde brachte. ${ }^{17}$ Die ausführliche Beschreibung bietet auch der erste Fortsetzer der Cosmas' Chronik an, der im Jahre 1141/1142 wahscheinlicher in dem Prager als Vyšehrader Kanonikerstift schrieb. ${ }^{18}$ Damit kontrastiert völlig der erhaltene Text der angeblichen Urkunde Vratislav II. Was die Erinnerung an den Akt der Gründung betrifft, ist das Privileg des Begründers äußerst wortkarg. Sogar wird nicht daran erinnert, dass eben Vratislav die Kirche erbauen ließ. Im Stiftungsprivileg fehlt eigentlich die Information, dass eben Vratislav der Stifter der Vyšehrader Kirche war. Neben allgemeinen Urkundenformeln steht im Privileg von den Handlungen des Herrschers nur der Umstand, dass er in die Hände des Vyšehrader Probstes die anschließend genannten Güter und Einnahmen übergab (contradidi). Ferner wird lediglich nur erwähnt, dass er die Kirche dem St. Peters Stuhl anvertraute (comendare) und den kurialen Zensus festsetzte. Nichts mehr. ${ }^{19}$

Wenn die Vyšehrader Chorrherren im 12. Jahrhundert Vorliebe für umfassende und schmuckvolle Narrationen hatten und zugleich vom ersten bis zum letzten Wort auch die Urkunde von Vratislav II. gefälscht haben, muss gefragt werden, warum sie in dieses

17 CDB I, S. 365-367, Nr. 384, bzw. Gründung der Kirche von Wischehrad, S. 252-254: Anno domminice incarntionis MLXX. dux Wratislaus [...] inspiratione divina commonitus monasterium in metropoli Boemie urbe Wissegrad vocata, que omnium terre illius civitatum quasi mater et domina est, Deo iuvente construendum pia mente proposuit. Ad cuius propositi efficientiam non mediocri animo consilia pertractans dignum duxit, quatenus monasterium, quod gratia Dei cooperante conficendum devote promiserat, sancte Romane ecclesie pontifici regendum omnique ab adversitate diligenter protegendum simul cum canonicis eiusdem ecclesie commendaret. Igitur Petrus, ecclesie sancti Georii prepositus, Romam missus devota nuncia sui ducis domino apostolico fideliter insinuavit. Quo audito venerabilis papa Alexander Deo gratias pro tam felici prefati principis desiderio retulit moxque synodum conovocavit, in qua LXXII episcopi fuerunt. Quibus postquam omnia predicti ducis verba recitavit, cuncti unanimi corde et ore glorificantes Deum, qui sanctam suam ecclesiam in toto orbe terrarum dilatare non cessat, responderunt: Amen. Dominus ergo papa Petrum prepositum dominio suo cum privilegio in hec verba remisit: Alexander, servus servorum Dei [...] annunciamus. Boemorum dux Wratizlaus [...] innotuit: eclesiam in honore salvatoris nostri [...] edificare cupio. [...] Igitur ad hec perficienda Iohannem, episcopum Tusculanensem, fundamentum dare nos [Alexander] misimus, in presentia ipse prefatus dux cophinos terra onustatos duodecim propriis humeris portasse videbatur. Locus ergo, in qua est erecta, Wissegrada cognominatur, quod sonat litteraliter: altior civitatibus. Quam sacrosanctam ecclesiam totius provincie caput dici, venerari sanximus, prediis, mancipiis, auro, argento ceterisque ornamentis decenter dititam comperimus. [...] Huius vero conditionis gratia cunctis celsior in eadem regione ut videretur ecclesiis, qualicunque apparamento VII cardinales altari sancti Petri ministrare student, mitra, sandaliis, simili modo ipsius ecclesie prepositum, presbyterum, diaconum, subdiaconum incedere precipimus. Laudes, qua sub diademate statutis diebus proclamare solemus, solummodo in ista ecclesia astante duce, summa diligentia Christum collaudare permittimus. Chrisma baptizandi, conserationem clericum, episcopus loci illius, invidia diaboli attactus, abnegare si presumpserit, nostri decreti iudicio apud quemlibet episcopum inveniat et accepiat, nemine autem prepediente omnem iniuriam in Romana synodo libere proclamet.

18 Kanounik vyšehradský. In: Fontes rerum Bohemicarum II. Ed. Josef Emler. Praha 1874, S. 201-237, hier S. 206-207: Wissegradense monasterium, quod pater eius, beatae memoriae rex Wratislaus, aedificavit pro anima sua et uxoris suae prolisque suae, collaudante et authoritate gloriosissimi papae [Alexandri] atque LXXII patrum. Qui sanctae Romanae ecclesiae praenominatus pontifex ad corroborandam eiusdem sacrae institutionis dignitatem per Johannem, Tuscolanensem episcopum, et per Petrum, praepositum sancti Georgii martyris, praedictae ecclesiae ministris, videlicet presbytero, diacono, subdiacono et etiam praeposito transmisit, et ad insigne apostolicae authoritatis eis perpetuo hiis uti concessit, sandalia et mitras. Hiis vero ita dispositis et ordinatis, idem rex supra memoratus hoc praedictum monasterium subdidit sanctae Romanae ecclesiae, quod tali modo fundavit, portans propriis humeris XII cophinos plenos lapidibus in honore salvatoris, ut Constantinus imperator fundavit Romanam ecclesiam. Zu dieser Quelle und seiner Provenienz Reitinger, L., Psal tzv. Kanovnik vyšehradský opravdu na Vyšehradě?, S. 635-668. 
Schlüsseldokument alle in der Gemeinschaft entwickelte Errinnerungen nicht einbezogen haben, wenn sie doch vor allem auf dieser Stelle nicht unerwähnt bleiben sollten. Obwohl eben die Stiftungsurkunde das wichtigste Schriftstück darstellt, begegnen wir dieser Information auf keiner Stelle des Dokuments. Lediglich diese Tatsache weist auch darauf hin, dass die Urkunde von Vratislav in ihrer Grundgestalt nicht die Schöpfung der Vyšehrader Schreiberwerkstätte im 12. Jahrhundert sein musste, sondern ein älteres schlichtes Schriftstück aus dem 11. Jahrhundert, das später nur korrigiert wurde. In diese Richtung deutet auch ein weiteres Detail, nämlich die Koroboration der Urkunde: „sigilli mei inpressione insignivi“.$^{20}$ Denn diese zählt zu den am häufigsten gebrauchten Koroborationen in den Urkunden des Kaisers Heinrich IV. (sigilli nostri impressione iussimus insigniri), die in vor allem in den Heinrichs Urkunden konstant ist, trotzdem hatte sie auch die bestimmte Variationen. ${ }^{21}$ Dieser Salier war der nahe Vebündete von dem Fürsten und König Vratislav II. ${ }^{22}$ und der Vratislavs Bruder Prager Bischof Jaromír Gebhard hatte zwischen 1077 und 1084 das Kanzleramt des Kaisers inne. ${ }^{23}$

Während im Falle der angeblichen Urkunde von Vratislav sich als äußerst wahrscheinlich erweist, dass ihr ein authentisches Dokument hervorging, im Falle des angeblichen päpstlichen Privilegs von Alexander II. handelt es sich um eine völlige Fälschung. ${ }^{24}$ Die älteste Überlieferung der Urkunde befand sich in der Abschrift in der Vyšehrader Interpolation in der gegenwärtig erloschenen Straßburger Handschrift der Cosmaschronik aus der Wende des 12. zum 13. Jahrhunderts..$^{25}$ Die Existenz des selbstständigen Exemplars der gefälschten Urkunde ist zuletzt in dem verachteten Eintrag der Vyšehrader Chorherren von 1482 belegt. ${ }^{26}$ Die Fälschung selbst beschreibt einerseits wie die Funda-

20 CDB I, S. 373, Nr. 387.

21 Zum Beispiel MGH Diplomata regum et imperatorum Germaniae VI. Heinrici IV. diplomata (= DD H IV) I. Bearb. von Dietrich von Gladiss - Alfred Gawlik. Berlin 1941-1978, S. 292, Nr. 231; S. 293, Nr. 232; S. 294, Nr. 233; S. 323, Nr. 253; MGH DD H IV II. Bearb. von Dietrich von Gladiss - Alfred Gawlik. Weimar 1959, S. 498, Nr. 373; S. 518, Nr. 391. Die häufigste Benutzung dieser Korroboration wurde auch im Wort- und Sachregister der Edition. MGH DD H IV III. Bearb. von Alfred Gawlik. Hannover 1978, S. 1030. Weiter vgl. Reitinger, L.: Vratislav, S. 164.

22 Reitinger, L.: Vratislav, S. 35-51.

23 Kalhous, David: Jaromír-Gebhard, pražský biskup a ř́̌šský kancléř (1038-1090). Mediaevalia historica Bohemica 9, 2003, S. 27-43; Reitinger, L.: Vratislav, S. 40f, 101-103.

24 Die ganze Verfälschung der Urkunde konstatierten schon Gustav Friedrich (CDB I, S. 366, Nr. 384); Krofta, Kamil: Kurie a církevni správa zemi českých v době předhusitské. ČČH 10, 1904, S. 15-27, 125-152, hier S. 132-133,135; Hrubý, V.: Tři studie, S. 163, Anm. 431; Fiala, Zdeněk: K otázce funkce našich listin do konce 12. století. SBFFBU C 10, 1960, S. 5-34, hier S. 14; Pleszczyński A.: Vyšehrad, S. 136; Bláhová, Marie, Založeni vyšehradské kapituly ve středověké historiografii, in: Královský Vyšehrad 2. Sborník příspěvků ke křestanskému miléniu a k posvěcení nových zvonů na kapitulním chrámu sv. Petra a Pavla, Praha 2001, S. 13-31, besonders. S. 21.

25 Cosmae Pragensis Chronica Boemorum. In: MGH SRG Nova Series II. Hg. von Bertold Bretholz unter Mitarbeit von W. Weingerger. Berolini 1923, S. LXVI-LXVIII; Wojciechowska, Maria, Ze studiów nad rękopisami Kosmasa. Sborník historický 5, 1957, S. 5-20, hier S. 8-9. Zu dieser memoria des Vyšehrader Stiftskapitels vgl. Bláhová, M.: Založení vyšehradské kapituly, S. 13-31, zu der handschriftlichen Überlieferung S. 14-15; Reitinger, L.: Vratislav, S. 181-192.

Reitinger, L.: Vratislav, S. 184-185. 
mente der Vyšehrader Kirche persönlich von Vratislav gelegt worden sind, ${ }^{27}$ wobei in den Editionen nicht erwähnt wird, dass die direkte literarische Vorlage in diesem Fall die sogenannte Konstantinische Schenkung war:

Konstantinische Schenkung ${ }^{28}$

„duodecim nos sciatis de eius fundamentis secundum numerum duodecim apostolorum cophinos terra onustatos propriis asportasse humeris; quam sacrosanctam ecclesiam caput et verticem omnium ecclesiarum in universo orbe terrarum dici, coli, venerari ac praedicari sancimus".
Die Urkunde des Papstes Alexander II. (Falsum $^{29}$

„prefatus dux cophinos terra onustatos duodecim propriis humeris portasse videbatur. Locus ergo, in qua est erecta, Wissegrada cognominatur, quod sonat litteraliter: altior civitatibus. Quam sacrosanctam ecclesiam totius provincie caput dici, venerari sanximus“.

Das Falsum des angeblichen Privilegs von Alexander II. mit der Datierung 9. Mai 1070 bestätigt insbesondere die Exemtion des Vyšehrader Kollegiatstiftes aus dem Kompetenzbereich des Prager Bischofs und seine direkte Unterordnung dem Papste, für die Jahresgebühr der Kanoniker in der Höhe von 12 Pfund Silber. ${ }^{30}$ Völlig ungewohnt ist nicht nur die Tatsache, dass die Fälschung natürlich nicht der Praxis der damaligen kurialen Kanzlei entspricht, sondern auch der Umstand, dass die päpstliche Exemtion eine Kirche erlangte, die weder erbaut noch geweiht war. Der Ausbau des Kanonikerstiftes der Heiligen Peter und Paul wurde erst 1079 beendet. In diesem Jahr wurde die Kirche, wie darauf Marie Bláhová aufmerksam machte, nach der Überlieferung der Vyšehrader Chorherren geweiht. ${ }^{31}$ Laut der Quellen des 13. und 14. Jahrhunderts wurde die Kollegiatskirche irgendwann im Juli geweiht, wo man die „dedicatio ecclesie“ feierte. ${ }^{32}$

27 Siehe Anm. 17. Zu diesem Akt weiter vgl. Reitinger, L.: Vratislav, S. 158-161; ders.: Die königlichen Insignien aus dem Kloster Pegau und die „Kronenopfer“. Frühmittelalterliche Studien, im Druck.

28 Constitutum Constantini. In: MGH Fontes iuris Germanici antiqui in usum scholarum separatim editi X. Ed. Horst Fuhrmann. Hannover 1968, S. 84. Die übernommenen Passagen sind hier mit Kursivschrift gekennzeichnet.

29 Gründung der Kirche von Wischehrad, S. 253.

30 Gründung der Kirche von Wischehrad, S. 252, 254: Anno domminice incarntionis MLXX. dux Wratislaus [...] monasterium in metropoli Boemie urbe Wissegrad [...] sancte Romane ecclesie pontifici regendum omnique ab adversitate diligenter protegendum simul cum canonicis eiusdem ecclesie commendaret. [...] Hoc itidem asylum tutamini beati Petri, principis apostolorum, cunctisque in eiusdem sede sessuris firmiter commendavit. Marcas XII de eadem ecclesia ad pedes universalis pape, quicumque erit, omni anno offerendas sub Christi testimonio destinavit.

31 Cronica Boemorum auct. canonico S. Blasii Brunsvicensis. In: MGH Scriptores (= SS) XXX-1. Ed. Oswald Holder-Egger. Hannoverae 1896, S. 37-43, hier S. 39: Wratizlaus dux [...] monasterium in metropoli Boemie urbe Wissegrad vocata construxit, et ab episcopali iurisdictione sub annuo censu marcarum XII domino pape singulis annis dando eximi procuravit et a Geverhardo, fratre suo, Pragensi episcopo, anno Domini MLXXIX. dedicari fecit. Vgl. Bláhová, M.: Založeni vyšehradské kapituly, S. 22f. Die Informationen über den Codex, in dem diese Quelle abgeschrieben wurde, versammelte Nass, Klaus: Geschichtsschreibung am Hofe Heinrichs de Löwen. In: Die Welfen und ihr Braunschweiger Hof im hohen Mittelalter. Hg. von Bernd Schneidmüller. Wiesbaden 1995, S. 123-161, hier S. 134-136.

32 CDB V-2. Edd. Jindřich Šebánek - Sáša Dušková. Pragae 1981, S. 363-364, Nr. 714; Hledíková, Zdeňka: Statuta vyšehradské kapituly z roku 1317. In: Královský Vyšehrad 4. Sborník příspěvků ze semináře 940 
Wir wissen mit Sicherheit, dass der Vyšehrader Kirche die Exemtion erst durch die im Jahre 1144 ausgestellte Urkunde Lucius II. bestätigt wurde. ${ }^{33}$ Aber auch die Interpretation dieses Schriftstücks ruft Unklarheiten hervor. Hier ist die urkundliche Bestätigung der kurialen Exemtion länger als ein halbes Jahrhundert nach der Stiftung der Kirche fraglich und darüber hinaus in einer Zeit, wo das Stiftskapitel ihre Hauptbeförderer und -gönner Vratislav II. (1061-1092) und Soběslav I. (1125-1140) einbüßte. ${ }^{34}$ Nicht eindeutig ist auch die Information im Schriftstück, dass zwar der nach Rom abgeführte Zensus der Kanoniker und ihre Exemtion bewilligt werden, zugleich wird aber erwähnt, dass die direkte Unterordnung von Vyšehrad dem Peters Stuhl „bereits bekannt“ ist (dinoscitur), somit kein erst jetzt zustande gebrachtes Verhältnis entstanden ist. ${ }^{35}$ Andererseits fehlt jedweder Hinweis auf ihr Alter und auf den vorherigen Papst, welcher dieses Vorrecht gewährte, was bei anderen päpstlichen Urkunden, die eine Bestimmung ihrer Vorgänger bestätigt haben, sehr häufig der Fall war.

Vordergründig begegnen wir hier dem Problem, ob die Vyšehrader Exemtion erst durch diese Schriftstücke - also durch die Urkunde von Lucius II. und der Fälschung des Dokuments von Alexander II. - sichergestellt wurde, oder ihnen eine ursprüngliche Papsturkunde vorausging. Man darf vor allem nicht daran vergessen, dass die Exemtion kein Vorrecht war, dass sich die Kanoniker unberechtigterweise usurpieren konnten. Die direkte Unterordnung dem päpstlichen Stuhl war ein Verhältnis, das im gewissen Maße (oder für eine bestimmte Zeit) von beiden Seiten akzeptiert werden musste, also vom Stift und von der Kurie, sowie vom Bischof, in dessen Diözese sich die gegebene Kirche befand. Dieses Thema hängt vor allem mit der Frage zusammen, in welcher Zeit und von welchem Papst die Kanoniker ihr erstes Privileg (oder eventuelle mündliche Bestätigung der Exemtion) erlangen konnten. Mit Sicherheit wissen wir, dass Vratislav Interesse an der päpstlichen Bestätigung der exemtionellen Stellung seiner Stiftung hatte. Auch die Kurie stellte sich zu dieser Frage bereitwillig. Das entnimmt man dem Antwortschreiben Gregor VII. vom März 1074, welche augenscheinlich die Vyšehrader Basilika betrifft. Die Aushändigung des beanspruchten Privilegs für die Fundation von Vratislav verschob aber der Papst in die Zeit nach dem Ausbau und Weihe der Kirche. ${ }^{36}$ Wir erwähnen schon, dass zur Weihe der Kirche der Heiligen Peter und Paul in Vyšehrad im Sommer 1079 kam. Zwar reisten an der Wende der Jahre 1079 und 1080 zwischen Prag und Rom zumindest zwei Botengruppen, wobei von Bewilligung der slawischen Liturgie

let královské kolegiátní kapitoly sv. Petra a Pavla na Vyšehradě. Hg. von Bořivoj Nechvátal. Praha 2012, S. 134-165, hier S. 153; vgl. Reitinger, L.: Vratislav, S. 192-193.

34 Zur Soběslavs Unterstützung der Vyšehrader Kirche vgl. CDB I, S. 111-115, Nr. 111; S. 405-406, Nr. 393; Vaníček, Vratislav: Soběslav I. Přemyslovci v kontextu evropských dějin v letech 1092-1140. Praha - Litomyšl 2007, vor allem S. 213f; Reitinger, L.: Vratislav, S. 163-170, 243-249.

CDB I., S. 139, Nr. 136: Wissegradensem ęclesiam sub beati Petri [...] fundata est et cuius iuris esse dinoscitur. Diese Tatsache, dass die bestätigte Exemtion der Vyšehrader Kirche in der Urkunde keine eingeordnete Neuheit ist, beobachtete schon Krofta, K.: Kurie a církevni správa, S. 134-136.

36 Gregorii VII Registrum. In: MGH Epistolae selectae in usum scholarum (= Epp. sel.) II-1. Ed. Erich Caspar. Berolini 1920, S. 89, Nr. I.61: De reliquiis et privilegio, unde nos rogasti, cum nuntiis tuis finita et perfecta ecclesia consecrationis consilium a nobis quesierit, voluntati tue satisfacere benigne procurabimus. 
und weiteren nicht näher spezifizierten Fragen gesprochen wurde, wie das Schreiben von Gregor vom 2. Januar 1080 zeigt $^{37}$; während der nächsten Monate nach der Synode von Brixen brach aber der böhmische Herrscher als ergebener Anhänger des Königs Heinrich IV. die Anerkennung des Pontifikats von Gregor VII. wie auch seiner Nachfolger ab. ${ }^{38}$ Dagegen respektierte Vratislav den kaiserlichen Gegenpapst Wibert von Ravenna (Clemens III.), welcher in das apostolische Amt in Rom im Jahre 1084 eingesetzt wurde..$^{39}$ In diesem Jahre 1084 und Monaten waren in Rom für Heinrichs und Clemens' Unterstützung auch das böhmische Heer und drei Přemysliden - der Bruder von Vratislav und Prager Bischof Jaromír, sowie Vratislavs Sohn Bořivoj ${ }^{40}$ und auch sein Neffe der Přemyslide Svatobor Friedrich, welcher zu dieser Zeit zum Patriarchen von Aquilea ernannt wurde. ${ }^{41}$ Der Chronist Cosmas erwähnt in dieser Zeit mehrere Male die Kontakte des přemyslidischen Hofes mit Clemens III., welcher insbesondere 1086 die Urkunde für den Prager Bischof herausgab, ${ }^{42}$ ferner verfügen wir über das wahrscheinlich echte Schreiben dieses Papstes an Vratislav. Obwohl der Pontifik in diesem Schreiben Vratislav die Würde des Königs nicht zuerkennt und ihn nur als „princeps“ (und nicht als König) bezeichnete, zeigt das Schreiben die innige Zuneigung gegenüber dem böhmischen Herrscher. $^{43}$

Wenn also der böhmische König für seine bedeutendste Stiftung die Bestätigung erlangte, welche die im Jahre 1079 geweihte Vyšehrader Kirche aus der gängigen Diözesanverwaltung ausnahm und die direkte Unterordnung des Kanonikerstiftes unter die Kurie bestätigte, konnte es sich vordergründig um ein Privileg oder mündliche $\mathrm{Zu}$ stimmung von Clemens III. handeln. Übrigens, wenn damals einige viel weniger bedeutende Stifter (z. B. der Schwiegersohn des Königs Wiprecht von Groitzsch) ein paar Jahre nach dem Ausbau ihrer Kirchen im Stande waren das kuriale Dokument, welches die Exemtion ihrer Fundation guthieß, für sich sicherzustellen, war es sicherlich auch für

37 Gregorii VII Registrum. In: MGH Epp. sel. II-2. Ed. Erich Caspar. Berolini 1923, S. 473-475, Nr. VII.11.

38 J. F. Böhmer, Regesta Imperii. (= RI) III. Salisches Haus 1024-1125. 2. Theil: 1056-1125. 3. Abt.: Die Regesten des Kaiserreichs unter Heinrich IV. 1056 (1050)-1106. 3. Lief.: 1076-1085. Nach Vorarbeiten von Tilman Struve neuberarbeitet von Gerhard Lubich unter Mitarbeit von Dirk Jäckel. Köln - Weimar - Wien 2016, S. 173-176, Nr. 1001, 1002; Vogel, Jörgen: Gregor VII. und Heinrich IV. nach Canossa. Zeugnisse ihres Selbstverständnisses. Berlin - New York 1983, S. 184-209; Cowdrey, Herbert E. J.: Pope Gregory VII: 1073-1085. Oxford 1998, S. 194-201; Robinson, Ian S.: Henry IV. of Germany. 1056-1106. Cambridge 1999, S. 198-201; Althoff, Gerd: Heinrich IV. Darmstadt 2013³, S. 167f; Ziese, Jürgen: Wibert von Ravenna. Der Gegenpapst Clemens III. (1084-1100). Päpste und Papstum 20. Stuttgart 1982, S. 54-64.

39 Ziese, J.: Wibert von Ravenna, S. 83-94, s. 105-106; Robinson, I. S.: Henry IV, S. 225-232; RI III-2/3, 3, S. 252-258, Nr. 1137-1140.

40 Den Aufenthalt des Bischofs Jaromír Gebhard von Prag im Rom beweist die Königs Heinrich IV. Urkunde vom 21. März 1084. MGH DD H IV II, S. 470, Nr. 356. Zur Teilnahme des böhmischen Heres und des Přemysliden Bořivoj an den Heinrichs Romzug weiter vgl. Reitinger, Lukáš: König Vratislav II. von Böhmen († 1092) in der Erinnerung des Klosters Pegau. In: Deutsches Archiv für Erforschung des Mittelalters 73, 2017, S. 481-526, hier S. 492-494, 496-503.

41 RI III-2/3, 3, S. 265-266, Nr. 1152.

42 Cosmae Pragensis Chronica Boemorum II. 38, 41, 51. In: MGH SRG Nova Series II, S. 140, $146,159$.

43 MGH Die Briefe der deutschen Kaiserzeit. V. Briefsammlungen der Zeit Heinrichs IV. Bearb. von Carl Erdmann - Norbert Fickermann. Weimar 1950, S. 387-389, Nr. 1. Zur Authentizität dieses Briefes zuletzt Reitinger, L.: Vratislav, S. 275-296. 
den viel bedeutenderen přemyslidischen König kein großes Problem ein solches Schriftstück zu erlangen. ${ }^{44}$

Wenn das aber der Fall war, standen die Kanoniker von Vyšehrad im 12. Jahrhundert vor einem großen Problem, denn insbesondere nach dem Sieg des gregorianischen Papsttums unter Paschalis II. wurde Wibert von Ravenna (Clemens III.) in Rom natürlich als unzählige Male verdammter Antichrist wahrgenommen. Viel sagend ist z. B. der Umstand, das Paschalis befahl seine Leiche aus dem Grabe auszugraben und sie in den Tiber zu werfen. ${ }^{45}$ Hätten sich also in den geänderten Verhältnissen oder auch später die Brüder von Vyšehrad für die Nachweisung ihrer kurialen Exemtion auf die Urkunde oder mündliche Zustimmung dieses verwerflichen Papstes berufen, würde es als Beleidigung und Verhetzung der wahren Stellvertreter des Heiligen Peters betrachtet. Natürlich würde dann Vyšehrad nicht die einzige geistliche Institution sein, welche vom Gegenpapst errichtet oder bewilligt wurde, denn auch andere Institutionen haben im 12. Jahrhundert dasselbe Problem lösen und bei den gregorianischen Päpsten die erneute Anerkennung anstreben müssen. Als Beispiel können die von Clemens gegründete Erzbistümer in Braga in Portugal oder Dubrovnik/Ragusa auf der Balkanhalbinsel genannt werden. Die Erzbischöfe von Ragusa mussten zu diesen Zwecken eine Fälschung der päpstlichen Gründungsurkunde auf den Namen eines anderen Pontifik herstellen, zufällig war es auch Alexander II. ${ }^{46}$

Die Zuneigung des Gegenpapstes Wibert mussten im 12. Jahrhundert auch viele andere kirchliche Institutionen in Italien aus ihrer Vergangenheit vertilgen. Zum Beispiel die Bistümer in Brescia, Luni, und Cremona oder das Stiftskapitel San Lorenzo sowie die zwei Klöster San Pietro und San Maria di Valdiponte in Perugia. ${ }^{47}$ Die Kanoniker in

44 Nur zu den Jahren 1061-1100 nennen wir aus der der Reihe der Beispele von erteilten päpstlichen Exemtionen Regesta pontificum Romanorum I. Ed. Philipp Jaffé. Lipsiae 1885, S. 586, Nr. 4687, Nr. 4691, S. 587, Nr. 4692; S. 588, Nr. 4712, S. 617, Nr. 4981, S. 640, Nr. 5209, S. 645, Nr. 5263, S. 662, Nr. 5392, S. 669, Nr. 5462, S. 677, Nr. 5545; zur Exemtion des Wiprechts von Groitzsch Klosters Pegau vgl. Codex diplomaticus Saxoniae regiae. I-2. Urkunden der Markgrafen von Meissen und Landgrafen von Thüringen. 1100-1195. Hg. von Otto Posse - Hubert Ermisch. Leipzig 1889, S. 8-9, Nr. 8; Annales Pegavienses et Bosovienses. In: MGH SS XVI. Ed. Georg H. Pertz. Hannoverae 1859, S. 234-270, S. 247-248. Algemein über dieses kuriale Institut Blumenstok, Alfred: Der päpstliche Schutz im Mittelalter. Innsbruck 1890; Kéry, Lotte: Klosterfreiheit und päpstliche Organisationsgewalt. Exemtion als Herrschaftsinstrument des Papsttums. In: Rom und die Regionen. Studien zur Homogenisierung der lateinischen Kirche im Hochmittelalter. Hg. von Jochen Johrendt Harald Müller. Abhandlungen der Akademie der Wissenschaften zu Göttingen, Neue Folge, phil. hist. Kl. 19. Berlin - Boston 2012, S. 83-144.

45 Ziese, J.: Wibert von Ravenna, S. 273; Longo, Umberto: A Saint of Damned Memory. Clement III, (Anti)pope. In: Framing Clement III. (Anti)Pope 1080-1100. Hg. von Umberto Longo - Lila Yawn. Reti Medievali Rivista 13. Firenze 2012, S. 137-151, hier S. 151; Sprenger, Kai-Michael: Der tote Gegenpapst im Fluss - oder wie und warum Clemens (III.) in den Tibera gelangte. In: Gegenpäpste. Ein unerwünschtes mittelalterliches Phänomen. Hg. von Harald Müller - Brigitte Hotz. Wien - Köln - Weimar 2012, S. 97-125; Ders.: The Tiara in the Tiber. An Essay on the damnatio in memoria of Clement III. (1084-1100) and Rom's River as a Place of Oblivion and Memory. In: Framing Clement III. Hg. von U. Longo - L. Yawn, S. 153-174; Yawn, Lila: Clement's New Clothes. The Destruction of Old S. Clemente in Rome, the Eleventh-Century Frescoes, and the Cult of (Anti)Pope Clement III. In: ebd., S. 175-205.

46 Ziese, J.: Wibert von Ravenna, S. 133, 161.

47 D’Acunto, Nicolangelo: Das Wibertinische Schisma in den Quellen des Regnum Italiae. In: Gegenpäpste. Hg. von H. Müller - B. Hotz, S. 83-96, hier S. 86-89. 
Bologna haben den unerwünschten wibertinischen Schatten in ihrer Vergangenheit auf dieselbe Weise gelöscht wie die bereits erwähnten Erzbischöfe von Ragusa. Im Bologneser Domkapitel verwandelten sie das Privileg von Clemens III. von 1084 in eine Urkunde von Gregor VII., die sich ins Jahre 1074 meldete. ${ }^{48}$

Wie Gerald Schwedler konstatierte, im Falle des Pontifikats von Wibert ist es in vielen Hinsichten berechtigter nicht von damnatio memoriae, sondern von deletio memoriae zu sprechen. ${ }^{49}$ Nur auf entlegenen Orten konnte an die Gunst des Papstes Clemens erinnert werden. Das galt aber sicherlich nicht für die Kanoniker von Vyšehrad, welche als Besatzung der exemten Kirche natürlich jedes Jahr im Kontakt mit der römischen Kurie waren und ihre privilegierte Stellung somit kaum von dem Umstand ableiten konnten, dass ihr Stifter Vratislav als den Papst Wibert von Ravenna anerkannte und offenkundig nur bei diesem Gegenpapst nach dem Ausbau und der Weihe der Vyšehrader Basilika die Exemtion in den 80. Jahren des 11. Jahrhunderts ansuchen konnte.

Insbesondere diese Zusammenhänge deuten darauf hin, dass auch Vyšehrad zu dem verbreiteten Phänomen der von Wibert kompromitierten geistlichen Institutionen gehörte, welche ihre Vergangenheit überarbeiten und die Erinnerungen an den verdammten Papst löschen mussten. Der Umstand, dass sich dieser Papst in näher nicht bekanntem Maße an der Festsetzung der direkten Unterordnung des Stiftskapitels von Vratislav unter die Kurie am wahrscheinlichsten beteiligte, stand möglicherweise hinter den Peripetien, die dazu führen, dass die Kanoniker neue Urkundenbestätigung erst von Lucius II. im Jahre 1144 erlangten. ${ }^{50}$ Die Urkunde gibt allgemein und lediglich vage an, dass die Unterordnung des Vyšehrader Kollegiatstiftes unter die Kurie bereits „bekannt“ ist, daher schon früher bestanden musste, es wird aber nicht näher erwähnt, unter welchem Papst dies geschah. Zugleich, wie es scheint, mussten die Brüder diesem Stand der Dinge ihre Vergangenheit anpassen: den wahrscheinlichen Anteil des antigregorianischen Papsttums löschen. Die Zeiten des usurpatorischen Papstes Clemens III. versuchte man höchstwahrscheinlich mit der Fälschung des Papstes Alexander II. zu überbrücken, wobei die Urkundenfälschung völlig unüblich den Papst ein ungewöhnlich freigebiges Privileg über die Verleihung der Exemtion einer Kirche herausgeben ließen, die noch nicht stand. ${ }^{51}$

$48 \mathrm{Zu}$ diesem und anderen ähnlichen Beispielen Schwedler, Gerald: Zur damnatio memoriae bei Gegenpäpsten. Chancen und Grenzen eine diachronen Vergleichs von Hippolyt (217-235) bis Felix V. (11439-1449). In: Gegenpäpste. Hg. von H. Müller - B. Hotz, S. 205-229, hier S. $217 f$.

49 Schwedler, G.: Zur damnatio memoriae, S. 215-216; D’Acunto, N.: Das Wibertinische Schisma, S. 84f.

50 CDB I, S. 138-140, Nr. 136.

51 CDB I, S. 365-367, Nr. 384; Gründung der Kirche von Wischehrad, S. 252-254. 


\section{Nejstarší vyšehradské listiny a jejich role v utváření kapitulní paměti}

Do dob počátků kapituly sv. Petra a Pavla na Vyšehradě, kterou založil v 60. a 70. letech 11. století český kníže a posléze král Vratislav II., se hlásí dvě domnělé listiny spojené se samotným fundátorem Vratislavem II. a papežem Alexandrem II. V případě údajných zakládacích listin krále Vratislava se na základě pozdněstředověkých pramenů zdařilo zjistit, že tento dokument byl v kapitule původně uchováván v pěti a nikoli pouze ve čtyřech dodnes dochovaných exemplářích. Nový obzor poznání o nejstarších vyšehradských archiváliích rovněž nabízí nedoceněné dřivější zjištění, že nejstarší verze údajně Vratislavovy listiny vznikla krátce po roce 1182, avšak ve svých sto záznamech o darovaných pozemcích a důchodech zahrnuje majetkovou situaci kapituly pouze ke konci 11. století a v soupisu zcela chybějí záznamy o donacích z 12. věku. Tato okolnost vedle dalších souvislostí přiznává váhu předpokladům, že tomuto falzu zřejmě opravdu předcházela pravá listina Vratislava II. z 11. století. Druhým dokumentem hlásícím se do časů zakladatele kapituly je zcela zfalšovaná listina papeže Alexandra II., která popisuje založení kapituly a potvrzuje kanovníkům výsady včetně kuriální exempce, přímé podřízenosti kostela papežskému stolci za roční poplatek 12 hřiven stříbra. V nových souvislostech se toto falzum a motivace jeho vzniku jeví, když přihlédneme k okolnosti, že určitý podíl na ustanovení výsad vyšehradského kostela zřejmě měl teprve protipapež Kliment III. (Wibert z Ravenny), 1084-1100, jenž se po vítězství gregoriánského papežství ve 12. století u samotné kurie a v řadě duchovních institucí stal obětí prokletí památky a úplného vymazání z paměti. 